\title{
Occupational Demand, Cumulative Disadvantage, AND Gender: DifFERENCES IN UNIVERSITY GRADUATES' EARLY CAREER EARNINGS
}

\author{
Michael R. Smith \\ SEAN WAITE
}

Abstract. A number of mechanisms contribute to the gender earnings gap - both its level and trends in it. We focus on three of them: occupational demand, the cumulation of disadvantage that originates in the unequal domestic division of labour, and labour market statuses which also may originate in the domestic division of labour. We show that changes in occupational demand associated with the dot-com boom and what followed it have caused substantial shifts in the relative earnings of young male and female university graduates. We provide evidence of how one consequence of the domestic division of labour - differences in hours worked by gender - contribute to the size and growth of the female earnings disadvantage. And, even in our generally young sample, human capital accumulation is more likely to be disrupted for women than for men. We identify several methodological and substantive implications of our results.

Keywords: Earnings, gender, university graduates, occupational demand, cumulated disadvantage, tech boom.

Résumé. Plusieurs mécanismes contribuent au niveau et à l'évolution de l'écart des revenus entre les hommes et les femmes. Nous en examinons trois: la demande professionnelle, le cumul de désavantages provenant de la division inégale du travail domestique et la situation du marché du travail. Nous montrons qu'une expansion de la demande professionnelle liée à la bulle technologique a considérablement modifié les revenus relatifs des jeunes diplômés et diplômées universitaires. Nos résultats suggèrent qu'une conséquence de la division du travail domestique - les différences dans le nombre d'heures travaillées selon le sexe - contribue au niveau moindre et à la croissance inférieure des revenus des femmes. Même dans notre échantillon généralement jeune, l'accumulation de capital humain est plus susceptible d'être perturbée pour les femmes que pour les hommes. Nous identifions plusieurs conséquences méthodologiques et subs- 
tantives de nos résultats.

Mots clés: Revenus, sexe. diplomés de l'université, demande professionnelle, désavantages cumulés, bulle technologique.

\section{INTRODUCTION}

U. niversity graduates account for a disproportionate share of research on the gender earnings gap (e.g., Davies, et al., 1996; Finnie and Wannell, 2004; Morgan, 2008; Weinberger, 2011; Li and Miller, 2012; Livanos and Pouliakas, 2012; Bredtmann and Otten, 2014; Suhonen, 2014; Koshy, et al., 2016). England (2010) provides a reason for this. The decline in the gap in the US in the 1980s (Blau and Kahn, 2000: 76), she argues, was caused by a shift by young women into more lucrative fields of study - in particular, medicine, law, and management. The higher earnings in these fields (and of university graduates in general) combined with educational homogamy made childcare affordable and, therefore, less disruptive to women's careers.

What happened in Canada was a bit different. The gender earnings gap also fell (Baker and Drolet, 2010) but most of the narrowing was at the lower end of the earnings distribution (Drolet, 2011: 5). This was caused, in part, by a decline in the availability of relatively well-paid unionized jobs in industries like manufacturing and mining mainly occupied by males with modest educations. The amount of narrowing at the top of the distribution was limited by the fact that some significant proportion of well-educated women were employed in occupations like education and health, where the gender earnings gap was already modest. This reduced the room for further improvement. Nonetheless, in Canada the gap was also reduced by a movement of young women into the same lucrative fields of study (Kay, et al., 2016; Zarifa, 2012; Association of Faculties of Medicine of Canada, 2011).

This shift's contribution to narrowing the gender earnings difference is one reason the university level is worth separate study. There are two others, linked to the mechanisms identified by England: occupational demand and the domestic division of labour. The effect of a shift in field of study choices, we will argue, is influenced by occupational demand. And the feasibility of childcare is only one family-related factor shaping careers. Hours of work matter too. Consider these two factors consecutively.

Earnings convergence substantially stalled from the early 1990 s. This was in part caused by government budgetary difficulties. A signifi- 
cant proportion of well-paid jobs are held by well-educated women in the public sector - particularly in health and education. Reduced hiring in these sectors in turn put downward pressure on, in particular, women's earnings (Frenette and Coulombe, 2007: 3) ${ }^{1}$. That is one example of the effects of occupational demand. For our purposes another, but somewhat neglected, change in occupational demand is associated with the tech-boom and its aftermath. We know that: i) women remain relatively absent from STEM disciplines - science, technology, engineering, and mathematics (Xie and Shauman, 2003; Turcotte, 2011; Morgan, et al., 2013; Mann and DiPrete, 2013) which tend to yield higher pay; ii) in the early 1990s the dot-com boom caused the demand to surge for those in computer science-related disciplines including electrical engineers hired to supply equipment (Wang, 2007; Senn, 2000). This translated into rapidly rising relative wages in these occupations and the use of immigrants to meet the increased demand (Picot and Hou, 2009; Bound et al., 2015). Increased demand for STEM graduates is likely to have favoured the relative earnings of men.

In 2001 the dot-com boom turned into a bust - immediately reflected in substantial falls in the share prices of dot-com companies. The demand for computer scientists and engineers fell. But, unlike share prices, relative earnings did not collapse. As Bound et al. (2015) show, after 2000 the earnings premium to computer science declined relative to the very end of the 1990s, fluctuated thereafter, but remained higher than it had been at the beginning of the 1990s, even after the Great Recession. One would expect any upward pressure on the gender earnings gap to weaken from 2001, but not to disappear.

Our second factor of interest is the implications of the domestic division of labour for careers in highly paid occupations. Higher earnings and homogamy, England argued, meant well-educated women could afford childcare. This, in turn, attenuated the negative effects of childbirth on their careers. So, while the average effect of having children is lower female earnings (e.g., Budig and England, 2001), that is now less apparent among the better educated. Another form of career disruption, probably linked to the domestic division of labour but not always to childrearing is hours of work. Some jobs held by graduates pay overtime rates for additional hours (in the public sector, in particular). More interesting for our purposes are jobs like lawyer, management consultant, accountant, and doctor that often require a willingness to work very long hours. The hours demands on lawyers do seem to contribute to the profession's gender earnings gap (e.g. McNabb and Wass, 2006). Conversely, part-

1. At the lower end of the educational distribution the commodities boom increased male earnings. 
time work not only reduces current earnings, it also tends to damage careers (Durbin and Tomlinson, 2010). There is abundant evidence of the contribution to the gender earnings gap of differences in hours of work (Abroms and Goldscheider, 2002; Reynolds, 2005; Maume, 2006; Reynolds, 2003: 1183; Cha, 2013; Cha and Weeden, 2014). Complementary to hours of work effects, disruption to continuous employment that may be linked to the domestic division of labour may slow the accumulation of human capital and also reduce women's relative earnings. We think that both these mechanisms warrant further examination.

There is advantage to studying the effects of occupational demand, hours worked and employment interruptions in early careers. As careers progress, some combination of seniority, bonuses, and commissions tend to detach pay-determination from market forces. This is why earnings fall so substantially when high seniority workers lose their jobs (Morissette, et al., 2013). Earnings at the beginning of a career are most likely to reflect the level of, and changes in, occupational demand. At the same time, the demand to work very long hours is often greatest in the early career, as young professionals demonstrate their bona fides, so to speak (Köszegi and Li, 2008) and, because of the domestic division of labour, those long hours take a greater toll on women (Keller, 2009; Kay, et al., 2016). Mechanisms of the sort that interest us are likely to be most easily detectable among early career employees.

\section{Data, Research Questions, And Methods}

Available in its confidential form from Statistics Canada's Research Data Centres, the National Graduates Survey (NGS) is well-suited for the assessment of early career effects on levels and trends in the gender earnings gap. Boudarbat and Connolly (2013) have used it for precisely that purpose. Their approach, however, differs from ours in several ways. First, they focus in particular on the share of the gap unexplained by the variables in their model. We, in contrast, focus on the role of the factors discussed above: i) the expression of occupational demand through field of study effects and ii) the domestic division of labour, including hours worked ${ }^{2}$. Second, and related to this, we model annual earnings rather than the hourly wage rate, for the reasons given in the previous section. Third, because of our focus on field of study effects, we exclude occupation and industry from our models. A large part of the mechanism linking

2. It should be clear that they do report field of study effects for their models that aggregate postsecondary graduates but do not do so for their separate analyses of college and university graduates. 
fields of study to earnings operates through industries and occupations. This means that Oaxaca-Blinder decompositions, the method both we and Boudarbat and Connolly use, will tend to underestimate the effects of fields of study since some part of their influence is picked up by industry and occupation.

The survey gathered data on a series of graduating classes of universities, colleges, and trade schools. Cohorts of graduates were identified at four or five year intervals. The 1986, 1990, 1995, and 2000 cohorts were all interviewed two and five years after graduation ${ }^{3}$. For these cohorts we can estimate both cross-sectional associations and changes in gender earnings differences in the early career. The 2005 and 2010 cohorts were only interviewed once - in 2007 and 2013 respectively. They do not allow panel analysis but do permit cross-sectional comparisons up to the recent past. We use these data to address three research questions.

- Did the tech-boom influence the size of the gender earnings gap?

- To what degree, and how, did hours of work contribute to the earnings gap?

- To what degree does the gender of university graduates interrupt the accumulation of human capital?

The first question follows from the general possibility that occupational demand effects have been insufficiently considered in previous research. The second question is linked to the broader issue of the domestic division of labour as source of female earnings disadvantage. The effects of marriage, child care, and hours are well-established. Previous studies on hours, however, have not estimated early career effects of changes in hours of work - reflecting early career demands on workers - on growth in earnings. Our data allow us to do that. The third question responds to the fact that the accumulation of human capital increases earnings. We know that gender influences that accumulation (e.g., Budig and England, 2001). Do disruptions to the accumulation of human capital show up in our very young and well-educated sample?

The total sample size is about 30,000 per cohort but we only use the university portion. University provides a fairly well-defined educational experience. Also, this group is most likely to have been influenced by the occupational demand shifts occasioned by the tech-boom. After ex-

3. Data were also collected for 1976 and 1982 cohorts. We have some concerns about the comparability of the questions used in the earlier surveys with the current ones. Consequently, we start with the 1986 cohort. This is the percentage difference interpretation of the -0.268 coefficient in Table 3 for 2000 . The percentage effects are calculated using the formula in Thornton and Innes (1989). 
cluding college and trade school graduates we have a sample of about 8,000 . In much of what follows we work with considerably fewer cases than this. For reasons we discuss shortly we use broader and narrower samples, but always with significant numbers of exclusions.

For most of our tables our dependent variable is the logarithm of annual earnings. Most earnings models use the hourly wage rate. But there are disadvantages to this operationalization. Consumption is substantially determined by earnings aggregated over some time period (weekly, monthly, annually). High hourly earnings combined with few hours will translate into limited consumption. Moreover, someone earning an annual salary in the upper part of the earnings distribution but reporting a very large number of hours of work may be misleadingly moved down in the distribution - misleadingly because the working hours are an accepted part of a job that offers very good prospects even if they drive some proportion of employees to other careers. The stereotypical young lawyer or accounting firm employee illustrates this well.

For one of our tables the dependent variables are two measures of labour force status. One is not in the labour force (NLF) versus employed and unemployed. People may be NLF because they enrolled in an educational program or for other reasons. We call this latter status residual NLF. The other is employed or in education versus unemployed or residually NLF (often called NEET - not in employment, education, or training). We use this table to address the third research question listed above.

Appendix Tables A and B contain descriptive statistics for selected variables for men and women using our broader sample. Among the controls available to us the work experience measures warrant comment. Months employed since graduation is available for all waves of the NGS. For the second wave of the four cohorts for which panel data are available there is also a question on whether the respondent had been continuously employed with the same employer - tenure. Because the role of work experience in earnings determination is well-established, where available we include both months employed and tenure. Note, however, that dropping the tenure variable had a negligible effect on the other coefficients.

Our research strategy is to exploit as many informative comparisons of the amounts and sources of gender differences in earnings as the data allow - cross-sectional using different samples and dynamic analyses for those cohorts for which we have panel data.

Our cross-sectional models of earnings use Oaxaca-Blinder decompositions and follow the convention of treating male earnings as the benchmark earnings category (Blinder, 1973; Oaxaca, 1973; Jann, 
2008). We focus specifically on the effects on the gap of differences in male and female characteristics. We have also run the analyses using a three-fold, pooling, procedure. The two sets of results are not noticeably different. The advantage of the Oaxaca-Blinder procedure is that it provides information on the sources of the gender earnings gap using models estimated separately for men and women; it does not average coefficients across genders as would be the case if we estimated gender effects with a dummy. Different contributors to the gender earnings gap are precisely what interest us.

For the analysis of labour force statuses we use logistic regression. All p-values, in all tables, are two-tail Huber-White robust estimates (White, 1980).

We reduced the initial sample of 8,000 university graduates by excluding those working in the US, those in the Northern Territories, and foreign students. There are small numbers of them and, by location or character, they substantially differ from the rest of the sample. In the earnings models we excluded those with annual earnings under $\$ 5,000$ (in 2005 dollars) because their labour market status is ambiguous - neither clearly in nor out of it; we also excluded those whose reason for working part-time was enrolment in an educational program.

Other inclusion/exclusion decisions attempt to come to grips with the complexity of the transition from university to employment. The NGS cohorts include all university graduates - bachelor's, master's, and doctoral, both vocational and academic. These are very different sorts of degrees. One might control for degree categories. But it is not obvious what would constitute suitable groupings. For example, is an MBA any more vocational than a Master's in economics or pharmacology? In addition, a significant proportion of bachelor's degrees serve to qualify for entry into programs like business, law, or medicine, the latter two normally lasting three or more years. So a graduate in, say, political science who pursued law would not be in the labour market two years after graduation which is when, except for the 2010 cohort, the first NGS interview would have taken place. MBAs are designed for completion in two years or less but may take longer. Or, those entering MBA programs may delay for a couple of years to accumulate savings. All this is to say that a significant proportion of bachelor's recipients will not be in the sample two years after graduation. A further complexity is that, in Quebec, entry into law and medicine without a previous bachelor's degree is common.

We address these problems by running the decompositions for three different within-cohort samples: all degree recipients in employment at both interview points; all bachelor's degree recipients in employment at both interview points; and, for the four cohorts for which we have 
panel data, all bachelor's degree recipients in employment at the second interview point, five years after graduation. The first sample mixes those with bachelor's and graduate degrees including degrees in law and medicine. The second sample excludes the graduate degrees and the postbachelor's vocational degrees like law and medicine. The third is a way of coming to terms with the large number of exclusions produced by the two previous criteria. It maximizes sample size. Analysis of three different samples provides a robustness check. It also reveals an interesting difference in results by sample which we discuss later.

Our panel analyses do not use fixed-effects specifications. We have only two data points for each panel. Consequently, case-specific dummies would substantially reduce the power of significance tests (Clark and Linzer, 2015). Instead we use hybrid models (Allison, 2005: 3238). These combine two sorts of information: between-effects averaged across the two survey points and within-effects for a set of explicitly included change variables - hours of work, marriage, and the arrival of a child. All these are likely to be related to the domestic division of labour and can be interpreted in the same way as fixed-effects coefficients. Again, these analyses are restricted to those who were employed both two and five years after graduation. A problem, then, with the NGS research design is that it does not allow us to run dynamic analyses of the sample that include some of the post graduate studies which are often likely to prove lucrative. Still, the range of methods we use - cross-sectional with varying sample composition along with dynamic models provides information on the issues we raise which, we think, warrants reasonable confidence in our conclusions.

\section{Cross-Sectional Analyses of Earnings across Cohorts}

Tables 1, 2, and 3 summarize the results from our Oaxaca-Blinder decompositions with the exclusions and inclusions described above. The tables provide the following: the size of the male earnings premium before adding any controls; the amount of the premium explained by field of study, without other controls; the amount of the premium explained by variables likely related to the domestic division of labour - hours, marital status, children, tenure, and experience, without other controls; and the amount of the premium explained by the complete models. The other controls are listed at the foot of the table. We discuss them shortly.

The first rows of the three tables show that men earned more than women in all years. The male advantage varied between a low of about $9 \%$ and a high of about $24 \%{ }^{4}$ Should these differences be considered 
large or small? Baker and Drolet (2010: 431) report an annual earnings difference of about $30 \%$ from the early 1990 s to the 2000s. In most years our differences are appreciably smaller. But remember, unlike them, we are dealing with a young sample. The gender earnings gap increases with age $(\mathrm{Wu}, 2007)$. Few in our sample would have experienced familyrelated career interruptions. Part of the earnings disadvantage of older women is caused by lower levels of education than men (Goldin and Katz, 2008: 248-253). With these considerations in mind, we think that even the $8 \%$ gap is appreciable. The $24 \%$ gap is unequivocally large.

For the first four cohorts, tables 1 (professional and bachelor's degree recipients) and 2 (only bachelor's degree recipients) contain information on the difference at two points. Strikingly, for both samples the disadvantage always grew from the first to the second survey point. All the increases are significant (p-value of 0.05 or lower). The increases range between 2 and 7 percentage points. Graduate women earned less than men and the size of the gap grew from two years after graduation to five years after it.

Work on gender earnings differences notes a decline in the gap over time in Canada and elsewhere (Drolet, 2011: 6; Blau and Kahn, 2006; Smith, 2012). In tables 1 and 2 , focus on the trend across the first survey points for the 1986 to 2000 cohorts and the single years for the 2005 and 2010 cohorts (the latter one year more after graduation than the others). There is a decline in the gender pay gap from 1988 to 1992, a very large rise from 1992 to 1997, a fall from 1997 to 2002, and rises from 2002 to 2007 and from 2007 to 2013. There is the same pattern for the four cohorts' with second survey points. The widely observed and broad decline did not occur for these samples of graduates over the 25 years studied. Moreover the last line of each table shows that, while usually smaller after the addition of controls, the gender earnings disadvantage is always significant and displays the same broad pattern as the raw differences.

Table 3 allows a further check for sample selection effects. Containing all those employed five years after graduation it has the largest N's. It reproduces the trends in raw differences of the previous two tables. Sample selection appears not to be a problem.

From the 1995 cohort on, the sizes of the raw differences are consistently larger in Table 2 than in Table 1: 2 percentage points larger in 1997, almost 4 percentage points in 2013. Remember, Table 1 includes graduates in law, medicine, and MBAs, fields of study increasingly populated by women. Table 2 eliminates those graduate degrees. Women's earnings disadvantage, it turns out, was larger in this narrower sample of bachelor's degree recipients. Table 4 will provide the reason for this. Before examining Table 4, consider the second and third rows of tables 1 to 3 . 
The second describes the contribution of fields of study to the gender earnings gap. Across all three tables, in most years their contribution is significant and large. Table 1 reveals small contributions in the early to mid $1990 \mathrm{~s}$ - about $2 \%$. This rises to $6 \%$ for the 1995 cohort, thereafter falling to about 4\% until in 2013 the contribution again became insignificant. Table 2, which we have already seen tends to reveal larger gender earnings gaps, also reveals contributions of field of study that are always larger than Table 1's - rising to $9 \%$ in 1997, and are present across all years. The larger sample in Table 3 produces a similar pattern to Table 2. Notwithstanding the flow of women into law, medicine, and management, fields of study contributed to the gender earnings gap, especially in the mid 1990s. Moreover, while not presented separately here (the estimates are available on request), the contributions of fields of study to the gap are significantly different across a number of years. Most importantly, the 1997 and 2000 contributions are significantly larger than are those for all preceding years; those for 2000 are larger than all succeeding years too. This is strong evidence of occupational demand effects in the later 1990 s.

The third row sums the contributions of variables likely to be associated with the domestic division of labour: work experience, tenure with current employer, marriage, children, and hours of work. Only in 1988 do these variables, in aggregate, make no contribution to the gender earnings gap of this young sample; thereafter they account for between 6 and 10 percent of it in Table 1, 5 and 9 percent in Table 2, and 7 and 8 percent in Table 3.

In Table 4 we look within the broader categories of tables 1 to 3, using the narrower sample (which excludes medicine, law, and MBAs). The results are striking. The entire field of study contribution to lower female earnings originated in two fields: Mathematics, Computer and Information Sciences; and Architecture, Engineering and Related Technologies. The contribution of the engineering disciplines increased fairly abruptly from 1997. We know that the dot-com boom pushed up the demand for engineering graduates from the mid 1990s. We also know that men remain overrepresented in that field of study. This shows up in our results. The gender earnings gap for university graduates increased because of it. Consistent with the aggregate evidence discussed earlier, the demand for those in the relevant fields of study remained strong after the subsequent bust. It only declined in 2013 which is the sole year for which we have post Great Recession data.

Table 2 produced larger field of study effects than Table 1. Remember, Table 1 contains well-paid graduates in medicine, law, and with MBAs. Table 2 is limited to Bachelor's degree holders. Women have 
increased their presence among those with graduate degrees. But they remain substantially absent from the lucrative STEM fields of study which shape the results in tables 2 and 3. This explains the differences in results across the two tables.

Now look at the cluster of domestic division of labour variables. For this young sample, five years after graduation at the most, marriage, children, tenure, or experience had no effect. We did not include geographic mobility in our cluster of domestic division of labour effects. It has, however, sometimes been argued that women have lower pay because they are less likely to switch jobs for career reasons (Booth, et al., 2003; Blackaby, et al., 2005; Lemistre and Moreau, 2009). We find no evidence of that in our sample. But, like other researchers, we find very strong evidence of an hours effect in all years. This difference in averages is produced by the fact that even in this young sample women were more likely to work part-time and less likely to work very long hours - over 50 per week, say. Women on average worked fewer hours than men. Interestingly, the effect got bigger from 1997. We return to this result shortly. The general point here is that, if it is true that the domestic division of labour causes different numbers of hours of paid employment by gender then the strong hours of work contribution to the earnings gap we find can be seen as confirmation of our second mechanism.

\section{The Cross-Sectional Analysis of Labour Force Statuses}

Table 5 addresses the issue of labour force participation. The top panel runs logistic regressions describing the effects of gender on labour force statuses without controls, the bottom panel with controls. The dependent variable in the top rows of the two panels is NLF (education plus residual NLF) versus being in the labour force. For most years the odds ratios are insignificant. However, where they are significant, men were between about 20 and 39\% less likely to be NLF than women. Adding controls increases the number of significant associations by one.

Those NLF because in education would mostly not be damaging their future labour market outcomes. If the gender difference in NLF reflects a larger presence of women in schooling the result above would not imply a subsequent gender earnings gap. This is addressed in the second row of each panel which describes the effects of gender on the likelihood of being in employment or education - the two ways of adding to human capital - versus unemployed or residually NLF. Before controls, half of the odds ratios are significant. Men were between about 30 and $60 \%$ more likely than women to be in employment or education. Adding 
controls reduces the number of significant associations. Still, where significant, these young, well-educated women were always less likely to be in human capital-enhancing statuses than their male counterparts. We know from inspection of the data that this difference was not produced by higher female unemployment rates. Rather, women were more likely than men to be residually NLF, mainly for what Statistics Canada calls 'personal' reasons.

Because this is a young well-educated sample its members were overwhelmingly employed. This both reduces the likelihood of finding significant associations and makes the ones we do report all the more striking.

\section{Hybrid Models of Changes in Pay by Gender}

The panel data for four of our cohorts allow us to estimate dynamic models. These provide another way to examine the two mechanisms that interest us. Our hybrid models yield estimates of average associations between variables measured cross-sectionally at the two panel points as well as fixed-effects equivalent estimates of selected change variables entered into the models. Allison (2005: 35-36) suggests that the former be treated with caution. Since we already have year-specific cross-sectional coefficients we ignore them and focus on the fixed-effects equivalents. We separately run the models for males and females. Table 6 contains the results. We confine our discussion to a limited number of variables with substantial and/or consistent effects of particular interest.

Our fixed-effects equivalent - 'within' - results reveal that getting married is associated with greater earnings growth for men in the first and last panel cohorts and for women in the last. In the first cohort having children is positively associated with earnings growth for men and negatively for women. These results yield some evidence of female earnings disadvantage as a result of marriage or childbirth (for marriage, two positive coefficients for men, one for women; for children, one positive coefficient for men, one negative coefficient for women). But, for this young, well-educated, sample, most of the coefficients are insignificant.

Hours of work are another matter altogether. Every increase of an hour worked is associated with an increase in earnings of between a bit less than one and a bit less than two percent. Consider the implications of that for respondents working sixty and thirty hours a week respectively. The association is always as large or larger for women as compared to men. Increases in hours worked were associated with large increases in earnings for both men and women, within each of the cohorts. But be- 
cause women were less likely to increase their hours of work than men, this hours effect tends to amplify the gender earnings gap. This change in hours effect is, as far as we know, new in the literature.

The hybrid models both confirm and amplify our previous results. That is, they suggest that where marriage and childbirth have any effect on the gender earnings gap in this young sample they worsen it. More importantly, hours of work not only display the cross-sectional contribution to earnings that we reported in the previous section. In addition, their effect on growth in earnings exacerbates the female disadvantage.

\section{Discussion And Conclusions}

Our results show that the shift in occupational demand associated with the tech-boom and its persistent effect on earnings after the bust have substantially influenced the gender earnings gap for this sample of young Canadian university graduates. Specifically, the gap exploded as the boom gathered pace, as did the size of the contribution to the gap of two fields of study - engineering and computer science. Previous research (Smith, Waite, and Durand, 2017) showed similar effects for graduates of colleges of various kinds, for which there is a derived occupational demand (technicians who work with engineers and computer scientists). Not surprisingly, and consistent with what one would expect, the associations for university graduates reported here are stronger than they are for their college counterparts.

Differences in hours of paid work and growth in hours of paid work made a large contribution to the earnings gap. We have no explanation for those hours effects other than the gender division of labour and other research cited above documents the connection between the domestic division of labour and hours worked. The change effect is interesting because it tells us that, for some employees, being able to respond to employer demands for extra hours is important for career development.

Finally, a small proportion of women - but one larger than that of men - was more likely to have spent part of their time after graduation residually NLF - not accumulating human capital.

In evaluating these results, note that our data source avoids the agecohort-period problem that complicates the interpretation of results from most data sets. Most of our respondents fell into a narrow age range; they all graduated in the same year, and we have cohorts that entered the labour force in different periods. This means that confounded agecohort-period effects are not a problem for us. 
What are the major implications of these findings? First, consider the role of occupational demand. The aggregate gender gap narrowed then (approximately) stabilized in both Canada and the US. The effect of occupational demand at the lower end of the occupational distribution has been acknowledged. Drolet has pointed out that most convergence occurred there and it seems clear that this is related to a decline in the demand for jobs normally occupied by blue collar males. Fuller (2005) and Frenette and Coulombe (2007) link the stalled convergence to budgetary difficulties experienced by Canadian governments that reduced the supply of jobs in health and education often occupied by university educated females (OECD, 2013:121).

This latter point is important. The balance of the supply of and demand for particular occupations need not, often will not, be stable. Governments go through hiring periods which put upward pressure on the earnings of educated women. But, the reverse is equally possible. This has implications for the interpretation of trends in earnings differences. The shift of women into some more lucrative fields of study no doubt reflects broader institutional change within the family and within educational institutions and in access to unionization. But the effects of those institutional changes should be considered fragile: they assume a particular distribution of occupational demands. The effects of the techboom provide strong evidence of this fragility. It created jobs requiring fields of study where women remain underrepresented. In doing so it pushed up the pay of those jobs. Consequently, notwithstanding whatever changes had occurred within families, educational institutions, and the unionization process, the gender earnings gap for the university educated exploded in Canada in the 1990s.

Now consider the domestic division of labour results. In this young, highly educated, sample it is not surprising that there is only limited evidence of marriage and child effects. But we know the following about the domestic division of labour. Household tasks are distributed unequally; the clearest evidence of this is the distinctly negative effects of children on the earnings of women in couples (e.g. Budig and England, 2001). This unequal distribution is present whether a couple is married or in a common-law relationship (Stafford, et al., 1976; Abroms and Goldscheider, 2002). This seems to begin in childhood and continue into young adulthood, including when both partners are students (Brayfield, 1992; Pittman and Paul, 2001). This suggests an hours of paid work constraint even on young women. The women in our sample did indeed work fewer hours than their male counterparts. And, our results show, fewer hours whether more part-time work or working standard rather than very long 
hours - was negatively associated with not only earnings but also earnings growth. The association, it should be clear was very strong indeed.

Finally, there are the labour force status results. Most young graduates go directly to employment. A good proportion acquires additional education. Some cannot find a job and experience unemployment. But the differences in unemployment between the men and women in our sample were small. That leaves residual NLF. A small proportion of our sample occupied this status. Still, that proportion was mainly comprised of women. Residual NLF will not normally be associated with the accumulation of human capital. This, then, is another contributor to the gender earnings gap.

Both occupational demand and hours of work directly influenced the gender earnings gap at the very beginning of university graduates' careers. Note, furthermore, that for the three cohorts for which we had information on earnings two and five years after graduation the gap grew. These three observations draw attention to the cumulativeness of gender earnings disadvantage. So do our labour force status results. They show that at several points in time a small but disproportionately female part of our sample was residually NLF. Earnings rise with work experience which these young, well-educated, women were not accumulating.

We know already that the gender earnings gap increases with age (Wu, 2007). This occurs because progress through the life course provides more opportunities for earnings-damaging experiences. Our results suggest that these experiences start early, right after graduation from university. Some may be offset later in life (Zhang, 2009); most probably will not. A theoretical implication of these results is that the gender earnings gap needs to be understood as an outcome of a cumulative process. DiPrete and Eirich (2006) and Ferraro, et al., (2008) have theorized on the likely importance of cumulation as a social process. Our results provide a concrete application.

There is, moreover, an interesting aspect of the hours of work result: while always significant their contribution to the earnings gap almost doubled in 1997 and remained higher than before 1997 (Table 4). We have already demonstrated a direct effect of the tech-boom on relative earnings. The increase in the size of the hours effect in the late 1990s may be an indirect effect. It is likely that tech firms provide less familyfriendly work environments than much of the health and education sectors. There is a large literature lamenting the family-unfriendliness provided by many jobs. Our results underline the fact that family-unfriendliness is likely to vary with industrial structure and jobs associated with it, that is, with occupational demand. Esping-Andersen (2002) made this point in a discussion of Sweden. That is to say, he associated the relative 
family-friendliness of jobs in Sweden with the country's large public sector (at the time he wrote).

Finally, there is a methodological implication to our results. In interpretations of gender earnings differences the idea of discrimination features prominently. The issue this raises is, how should discrimination be measured? Quite a lot of research infers it from residual variance after relevant variables have been controlled (e,g., Blau and Kahn, 2006; Pfeifer and Sohr, 2009; Weinberger, 2011; Castenetti and Rosti, 2013). Other research - for example, Budig and England (2001) on the wage penalty for motherhood - shows that the gender earnings gap is an outcome of the cumulation of a series of career-damaging experiences. Our results suggest that this process of cumulation begins early. Now, surveys can include retrospective questions on the factors we identified as being likely to cumulate disadvantage: interruptions to education and employment, a smaller or absent marriage premium for women, and the effects of hours of paid employment. But even when information on all of these factors is available in a survey it is unlikely that, say, a 50 year old will accurately recollect her or his hours of work 25 years earlier. This matters because the career damage from working shorter hours is likely to be long term; gender differences at 50 may have originated in life experience some 25 years earlier. This, then, is a source of measurement error in models of gender earnings differences. That measurement error will be a source of part of the residual. Results may still be interpretable as discrimination. But the residual itself is a profoundly flawed measure of it.

\section{REFERENCES}

Abroms, Lorien C., and Frances K. Goldscheider. 2002. "More work for mother: How spouses, cohabiting partners and relatives affect the hours mothers work." Journal of Family and Economic Issues 23 (2): 147-166.

Allison, Paul D. 2005. Fixed Effects Regression Methods for Longitudinal Data Using SAS. Cary NC: SAS Press.

Association of Faculties of Medicine of Canada. 2011. Canadian Medical Educations Statistics 33: https://afmc.ca/sites/default/files/documents/en/ Publications/CMES/Archives/CMES2011Vol33.pdf (accessed June 12, 2019).

Baker, Michael, and Marie Drolet. "A new view of the male/female pay gap." Canadian Public Policy/Analyse de politiques 36 (4): 426-464.

Blackaby, David, Alison Booth, and Jeff Frank. 2005. "Outside offers and the gender pay gap: Empirical evidence from the UK academic labour market." Economic Journal 115 (501): F81-F107. 
Blau, Francine D., and Lawrence M. Kahn. 2000. "Gender differences in pay." Journal of Economic Perspectives 14 (4): 75-99.

Blau, Francine D., and Lawrence M. Kahn. 2006: "The U.S. gender pay gap in the 1990s: slowing convergence." Industrial and Labor Relations Review 60 (1): 45-66.

Blinder, Alan S. 1973. "Wage Discrimination: Reduced Form and Structural Estimates." Journal of Human Resources. 8 (4): 436-455

Booth, Alison, Marco Francesconi, and Jeff Frank. 2003. "A sticky floors model of promotion, pay, and gender." European Economic Review 47 (2): 295 322.

Boudarbat, Brahim, and Marie Connolly. 2013. "The gender wage gap among recent post-secondary graduates in Canada: a distributional approach." Canadian Journal of Economics 46 (3): 1037-1065.

Bound, John, Breno Braga, Joseph M. Golden, and Gaurav Khanna. 2015. "Recruitment for foreigners in the market for computer scientists in the United States.” Journal of Labor Economics 33 (3): S187-S223.

Brayfield, April A. 1992. "Employment resources and housework in Canada." Journal of Marriage and Family 54 (1): 19-30.

Bredtmann, Julia, and Sebastian Otten. 2014. "Getting what (employers think) you're worth: Evidence on the gender gap in entry wages among university graduates." International Journal of Manpower 35 (3): 291-306.

Budig, Michelle J., and Paula England. 2001. "The wage penalty for motherhood." American Sociological Review 66 (2): 204-225.

Castagnetti, Carolina, and Luisa Rosti. 2013. "Unfair tournaments: Gender stereotyping and wage discrimination among Italian graduates." Gender and Society 27 (5): 630-658.

Cha, Youngjoo. 2013. "Overwork and the persistence of gender segregation in occupations." Gender and Society 27 (2): 158-184.

Cha, Youngjoo, and Kim A. Weeden. "Overwork and the slow convergence in the gender gap in wages." American Sociological Review 79 (3): 457484.

Clark, Tom, and Drew Linzer. 2015. "Should I use fixed or random effects?" Political Science Research and Methods 3 (2): 399-408.

Davies, Scott, Clayton Mosher, and Bill O’Grady. 1996. "Educating women: Gender inequalities among Canadian university graduates." Canadian Review of Sociology and Anthropology 33 (2): 125-142.

DiPrete, Thomas A., and Claudia Buchmann. 2013. The Rise of Women: The Growing Gender Gap in Education and what it means for American Schools. New York: Russell Sage Foundation. 
DiPrete, Thomas A., and Gregory M. Eirich. 2006. "Cumulative advantage as a mechanism for inequality: A review of theoretical and empirical developments." Annual Review of Sociology 32: 271-297.

Drolet, Marie. 2011. "Why has the gender wage gap narrowed?" Perspectives on Labour and Income 23 (1): 5-15.

Durbin, Susan, and Jennifer Tomlinson. 2010. "Female part-time managers: networks and career mobility." Work, Employment and Society 24 (4): 621-640.

England, Paula. 2010. "The gender revolution: Uneven and stalled." Gender and Society 24 (2): 149-166.

Esping-Andersen, Gøsta. 2002. "Towards a post-industrial gender contract." Pp.109-128 in Peter Auer and Sandrine Cazes (edsd.), Employment Stability in and Age of Flexibility: Evidence from Industrialized Countries. Geneva: ILO.

Ferraro, Kenneth F., Tetyana Pylipiv Shippee, and Markus H. Schafer. 2008. "Cumulative

inequality theory for research on aging and the life course." Pp. 413-433 in Vern L.Bengtson, Gaphna Gans, and Norella Putney (eds.), Handbook of Theories of Aging ( $2^{\text {nd }}$ ed.), NY: Springer.

Finnie, Ross, and Ted Wannell. 2004. "Evolution of the gender earnings gap among Canadian university graduates." Applied Economics 36 (17): 1967-1978.

Fuller, Sylvia. 2005. "Public sector employment and gender wage inequalities in British Columbia: Assessing the effects of a shrinking public sector." Canadian Journal of Sociology 30 (4): 405-439.

Frenette, Marc, and Simon Coulombe. 2007. "Has higher education among young women substantially reduced the gender gap in employment and earnings?" Analytical Studies Branch Research Paper Series No.301, Statistics Canada.

Goldin, Claudia, and Lawrence F. Katz. 2008. The Race Between Education and Technology. Cambridge, Massachusetts: Harvard University Press.

Jann, Ben. 2008. "A Stata implementation of the Blinder-Oaxaca decomposition." ETH Zurich Sociology Working Paper No.5.

Kay, Fiona M., Stacey L. Alarie, Jones K. Adjei. 2016. "Undermining gender equality: Female attrition from private law practice." Law and Society Review 50 (3): 766-801.

Keller, Rita. 2009. "Staff turnover: Still a vital issue for CPA firms. Acounting Office Management and Administration Report 9: 2-4.

Koshy, Paul, Richard Seymour, and Mike Dockery. 2016. "Are there institutional differences in the earnings of Australian higher education graduates?" Economic Analysis and Policy 51: 1-11. 
Köszegi, Botond, and Wei Li. 2008. "Drive and talent.” Journal of the European Economic Association 6 (1): 210-236.

Lemistre, Philippe, and Nicolas Moreau. 2009. "Spatial mobility and returns to education: Some evidence from a sample of French youth." Journal of Regional Science 49 (1): 149-176.

Li, Ian W., and Paul W. Miller. "Gender discrimination in the Australian graduate labour market." Australian Journal of Labour Economics 15 (3): 167199.

Livanos, Ilias, and Konstantinos Pouliakas. 2011. "Education segregation and the gender wage gap in Greece." Journal of Economic Studies 39 (5-6): 554-575.

Mann, Allison, and Thomas DiPrete. 2013. "Trends in gender segregation in the choice of science and engineering majors." Social Science Research 42 (6): 1519-1541.

McNabb, Robert, and Victoria Wass. 2006. "Male-female earnings differentials among lawyers in Britain: A legacy of the law or a current practice?" Labour Economics 13 (2): 219-235.

Morgan, Laurie A. 2008. "Major matters: A comparison of the within-major gender pay gap across college majors for early-career graduates." Industrial Relations 47 (4): 625-650.

Morgan, Stephen L., Dafna Gelbgiser, and Kim A. Weeden. 2013. "Feeding the pipeline: Gender, occupational plans, and college major selection." Social Science Research 42 (4): 989-105.

Morissette, René, Hanqing Qiu, and Ping Ching Winnie Chan. "The risk and cost of job loss in Canada, 1978-2008." Canadian Journal of Economics 46 (4): 1480-1509.

OECD. 2013. Government at a Glance. Paris: OECD Publishing.

Oaxaca, Ronald. 1973. "Male-Female Wage Differentials in Urban labor Markets." International Economic Review. 14 (3): 693-709.

Pfeiffer, Christian, and Tatjana Sohr. 2009. "Analysing the gender wage gap (GWG) using personnel records." Labour 23 (2): 257-282.

Picot, Garnett, and Feng Hou. "Immigrant characteristics, the IT bust, and their effect on entry earnings of immigrants." Analytical Studies Branch Research Paper Series No. 315. Statistics Canada 11F0019M.

Pittman, Joe F., and Otto Paul. 2001. "Negotiating time spent in housework in early marriage: Tense and non-tense discussions." Pp. 311-340 in K. Daly (ed.), Minding the Time in Family Experience: Emerging Perspectives and Issues. Oxford: Elsevier.

Reynolds, Jeremy. 2003. "You can't always get the hours you want: Mismatches between actual and preferred work hours in the U.S." Social Forces 81 (4): 1171-1197. 
Reynolds, Jeremy. 2005. "In the face of conflict: Work-life conflict and desired work hour adjustments." Journal of Marriage and the Family 67 (5): 1313-1331.

Senn, James A. 2000. "Electronic commerce beyond the 'dot com' boom." National Tax Journal 53 (3): 373-383.

Smith, Mark. 2012. "Social regulation of the gender pay gap in the EU." European Journal of Industrial Relations 18 (4): 365-380.

Michael R. Smith, Sean Waite, and Claire Durand. 2017. "Gender differences in the earnings produced by a middle range education: The case of Canadian 'colleges"”. Social Science Research 66: 140-153.

Stafford, Rebecca, Elaine Backman, and Pamela Dimona. 1977. "The division of labor among cohabiting and married couples." Journal of Marriage and the Family 39 (1): 43-57.

Suhonen, Tuomo. 2014. "Quality of higher education and earnings: Evidence from Finland using field-of-study measures." International Review of Applied Economics 28 (1): 22-44.

Thornton, Robert J., and Jon T. Innes. 1989. "Interpreting semilogarithmic regression coefficients in labor research." Journal of Labor Research 10 (4): 443-447.

Turcotte, Martin. 2011. "Women and Education." Pp. 5-26 in Women in Canada: A gender-based statistical report. Statistics Canada 89-503.

Wang, Zhu. 2007. "Technological innovation and market turbulence: The dotcom experience." Review of Economic Dynamics 10 (1): 78-105.

Weinberger, Catherine J. 2011. "In search of the glass ceiling: Gender and earnings growth among U.S. college graduates in the 1990s." Industrial and Labor Relations Review 64 (5): 949-980,

White, Halbert. 1980. "A heteroskedasticity-consistent covariance matrix estimator and a direct test for heteroskedasticity." Econometrica 48 (4): 817-830.

Wu, Huoying. 2007. "Can the human capital approach explain life-cycle wage differentials between races and sexes." Economic Inquiry 45 (1): 24-39.

Zarifa, David. "Choosing fields in an expansionary era. Comparing two cohorts of baccalaureate degree-holders in the United States and Canada." Research in Social Stratification and Mobility 30 (3): 328-351.

Zhang, Xuelin. 2009. "Earnings of women with and without children." Perspectives on Labour and Income. 21 (2): 5-13. 


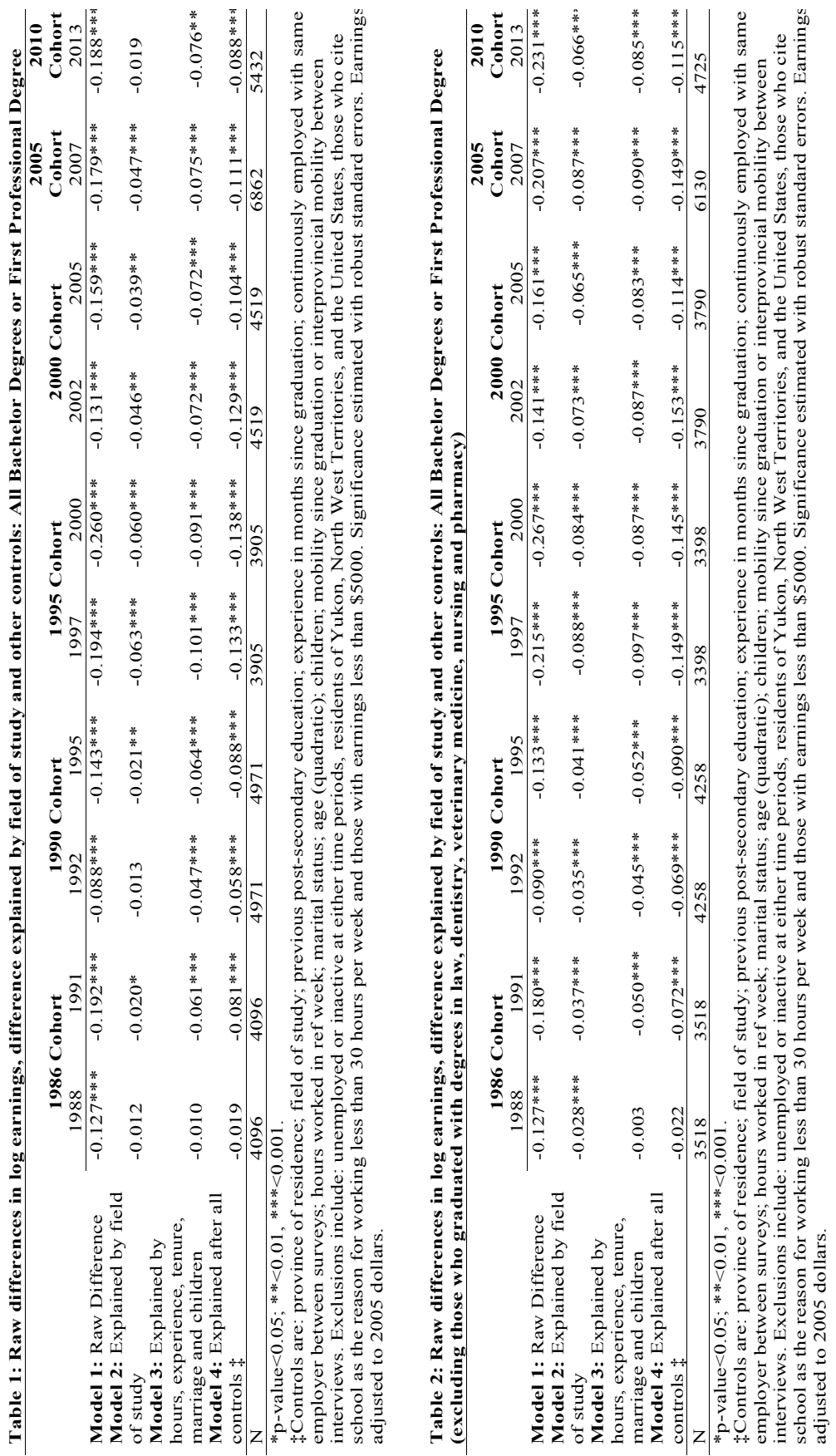


186 C) Canadian Journal of Sociology/Cahiers canadiens de sociologie 44(2) 2019

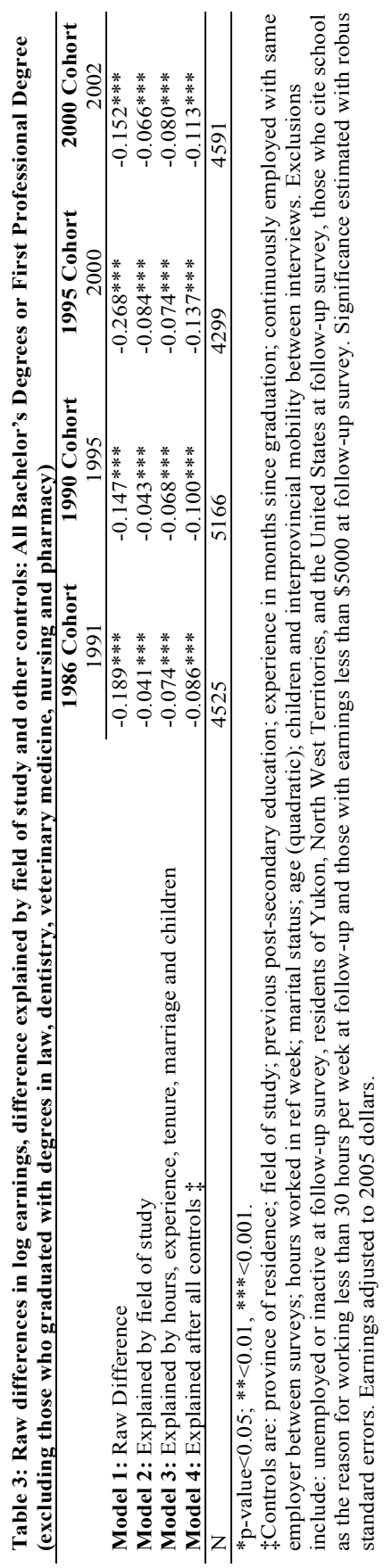




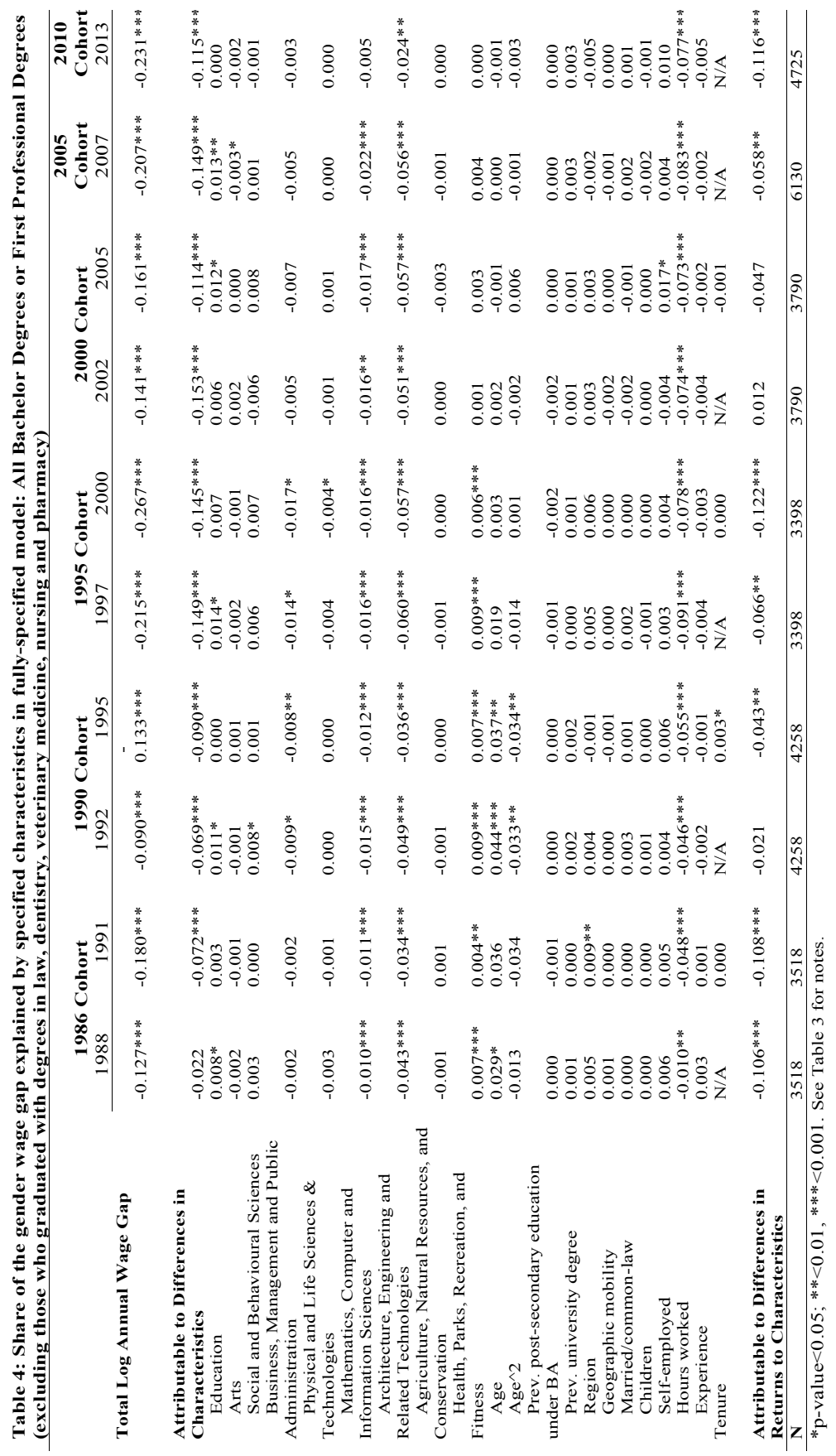




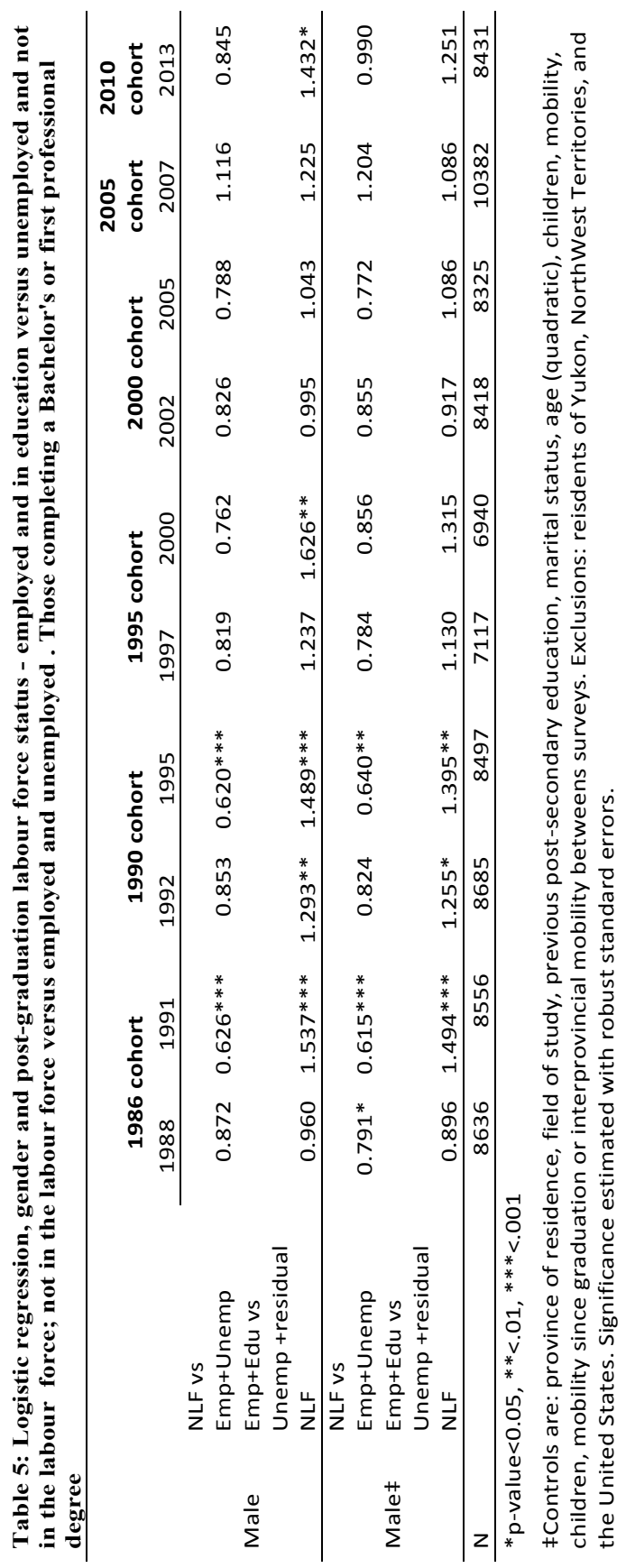




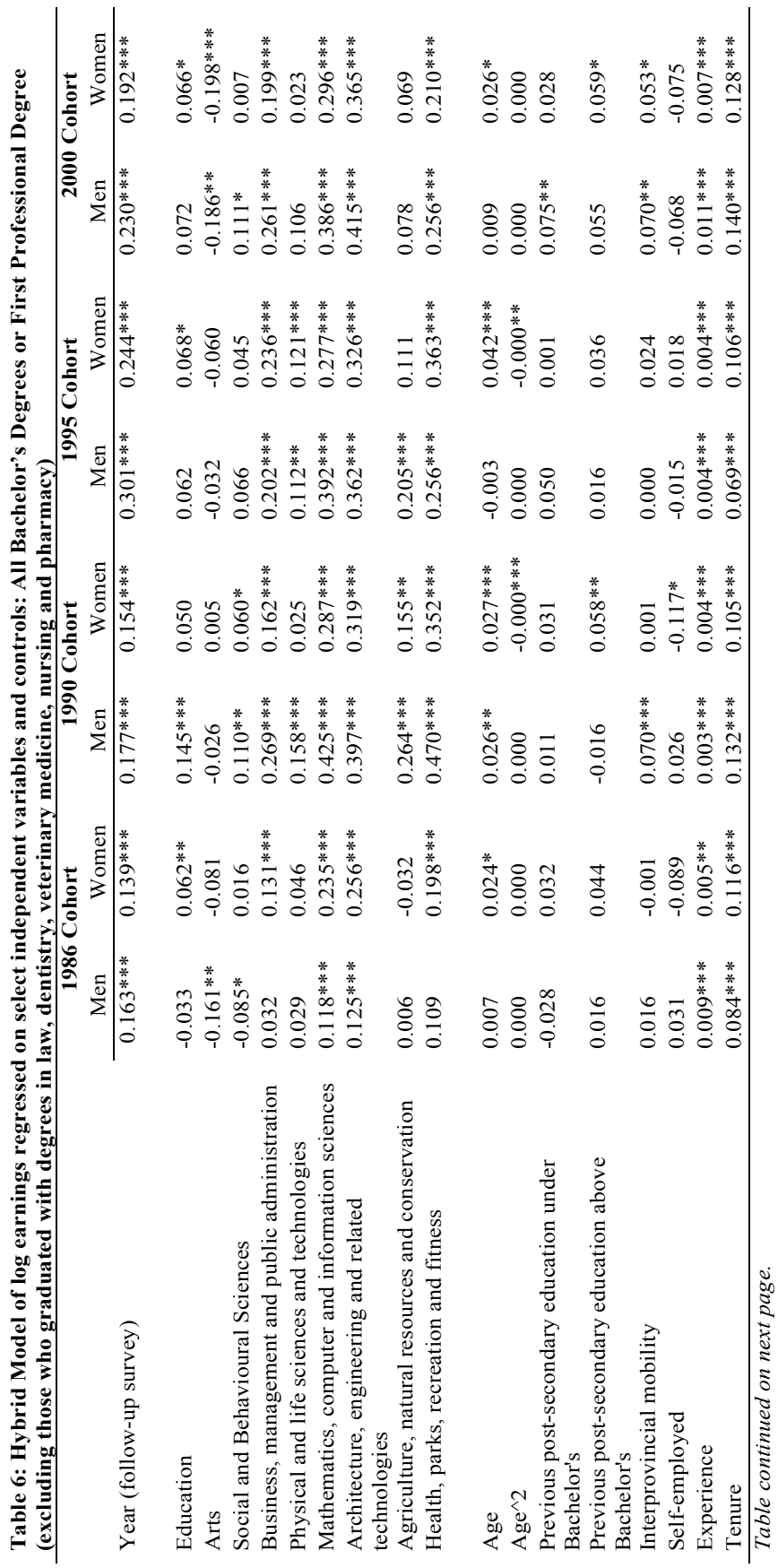




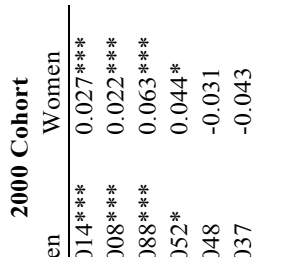

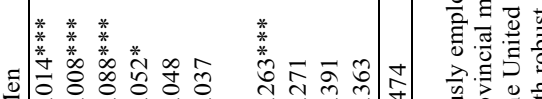
$\sum \mid \begin{array}{llllll}0 & 0 & 0 & 0 & 0 & 0\end{array}$

亡

बूँ

至

*

ڤั

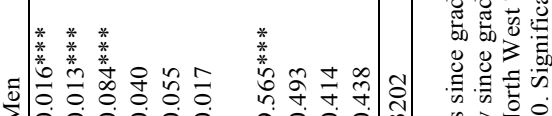

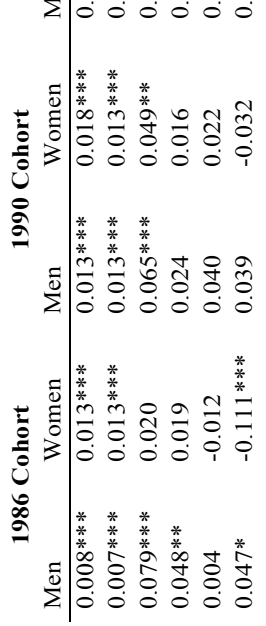

* *

은 육ำ

के

*

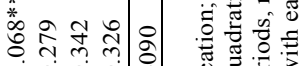

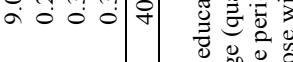

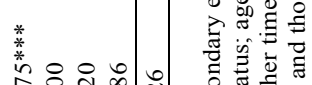

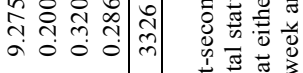

की

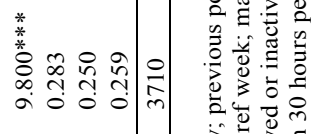

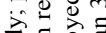

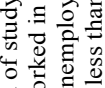

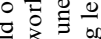

0

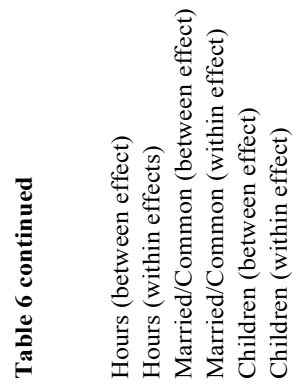

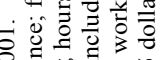

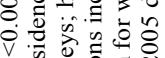

*

iी 0 क

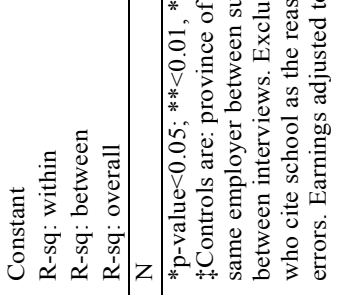




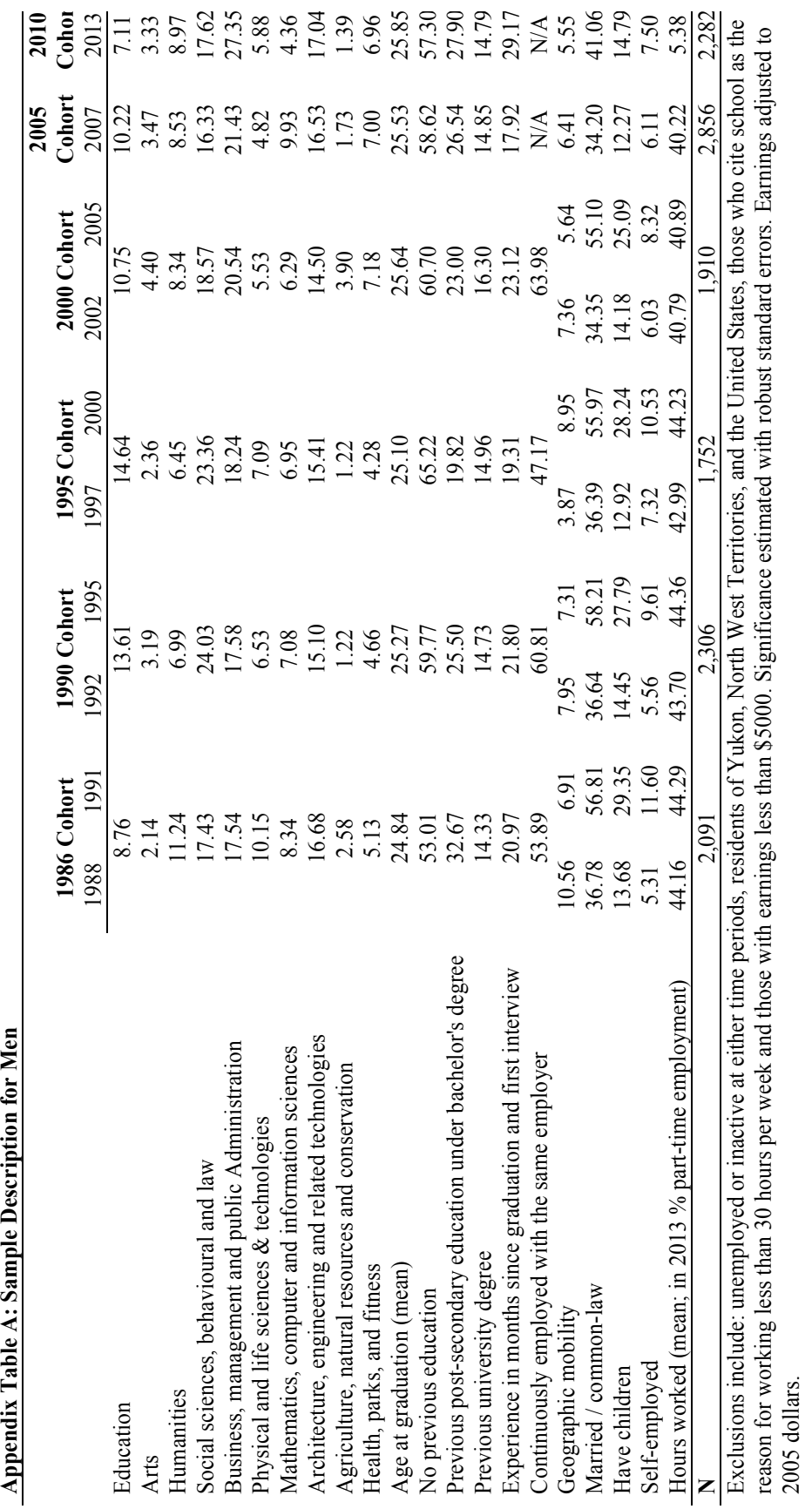




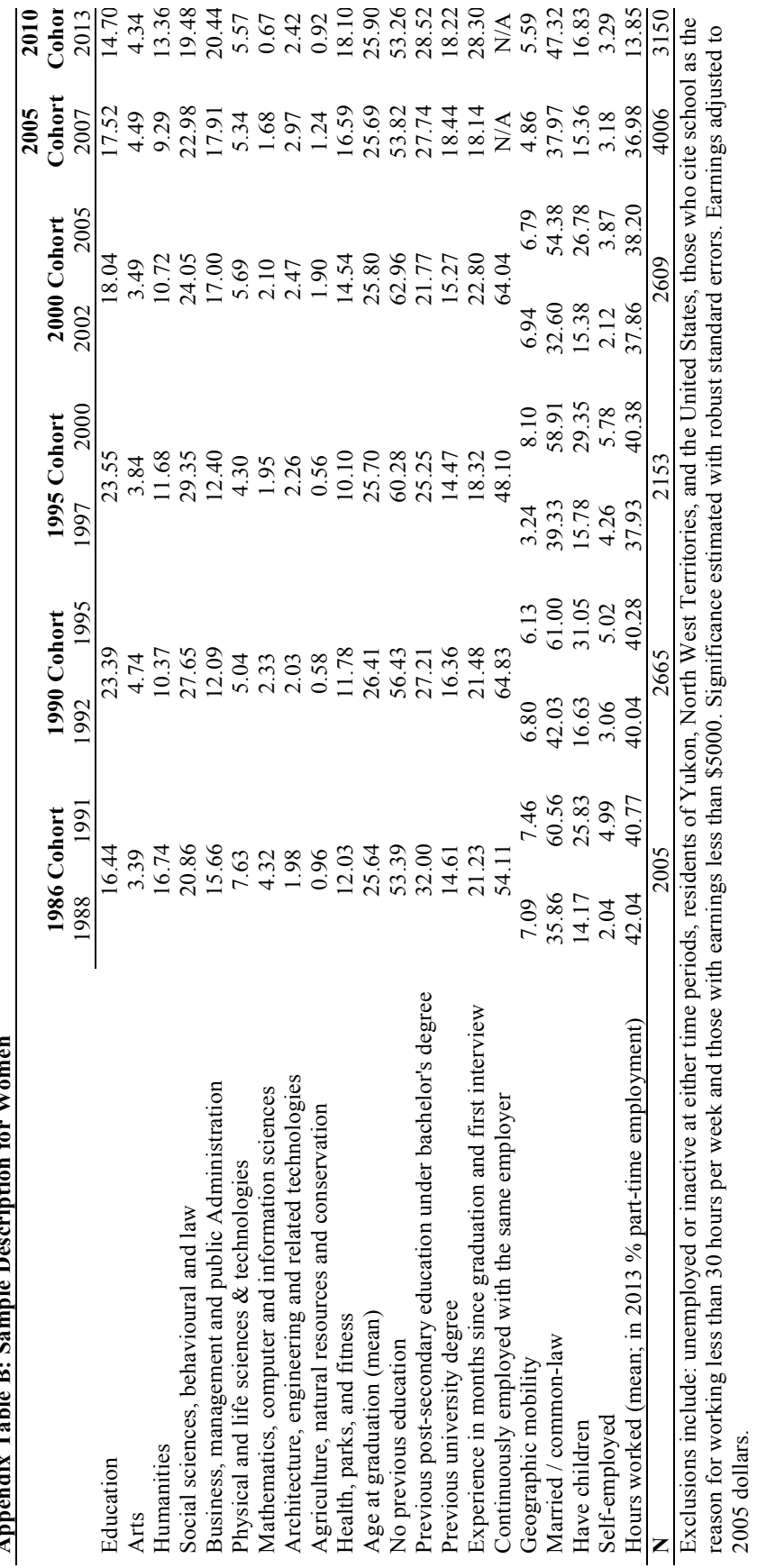


Michael R. Smith has published extensively on labour markets. In addition to gender and earnings, subjects examined include immigrant adaptation, job-loss and income, the effects of Quebec's training policies, productivity and wages, the effects of globalization, income inequality, and labour market flexibility. Current research has shifted to capital markets, with particular reference to the 2007 financial crisis.

Email: michael.smith@mcgill.ca

Sean Waite's research explores how gender and sexual orientation shape human capital acquisition, field of study and occupation choice, and earnings in Canada. He also examines returns to higher education, with a particular interest in the labour market outcomes of doctoral graduates. His research can be found in Gender \& Society, Social Science Research, Canadian Review of Sociology and The Canadian Journal of Higher Education.

Email: swaite3@uwo.ca 
194 C) Canadian Journal of Sociology/Cahiers Canadiens de Sociologie 44(2) 2019 